\title{
Cinética de fermentação ruminal in vitro de silagens de híbridos de sorgo
}

\author{
[Ruminal fermentation kinetics of sorghum hybrid silages] \\ T.C. Silva ${ }^{1}$, E.M. Santos ${ }^{2}$, C.H.O. Macedo ${ }^{2}$, M.A. Lima ${ }^{3}$, J.A.G. Azevedo ${ }^{3}$, \\ R.M.A. Pinho ${ }^{2}$, A.F. Perazzo ${ }^{2}$, J.S. Oliveira ${ }^{2}$ \\ ${ }^{1}$ Universidade Federal de Viçosa - Viçosa, MG \\ ${ }^{2}$ Universidade Federal da Paraíba - Areia, PB \\ ${ }^{3}$ Universidade Estadual de Santa Cruz - Ilhéus, BA
}

\begin{abstract}
RESUMO
Objetivou-se com esta pesquisa avaliar as silagens de 23 híbridos de sorgo por meio da técnica in vitro semiautomática de produção de gases. Foi utilizado o delineamento inteiramente ao acaso, com 23 tratamentos e três repetições, sendo os tratamentos as silagens de híbridos de sorgo. Os híbridos foram cultivados na estação experimental do Instituto Nacional do Semiárido (INSA), no município de Campina Grande - PB. A produção de gases foi estimada por intermédio do modelo logístico bicompartimental, ajustado às curvas de produção cumulativa de gases. Com relação ao volume final de carboidratos fibrosos (VfCF), houve efeito de híbrido $(\mathrm{P}<0,05)$, com resultados variando de 105,99 a $144,53 \mathrm{~mL} / \mathrm{g}$ de MS. Os valores de taxa de degradação dos carboidratos fibrosos (KdCF) variaram $(\mathrm{P}<0,05)$, e o híbrido 866041 apresentou o maior resultado $0,015 \mathrm{~h}^{-1}$. Os valores de volume final total (VfT) variaram $(\mathrm{P}<0,05)$, e os híbridos 870085, Volumax e XBS 60329 apresentaram maiores $(\mathrm{P}<0,05)$ valores de VfT em relação aos demais. Pela análise multivariada, foram formados seis grupos distintos. O grupo 2, composto pelos híbridos 22 (Volumax) e 23 (XBS60329), apresentou os maiores valores médios para os volumes de gás, tanto para os carboidratos fibrosos quanto para os não fibrosos. O grupo 4, composto pelo híbrido 1 (866005), apresentou as menores médias para volume de gás produzido e o maior lag time (3,15 horas). Todos os híbridos estudados apresentam potencial para ensilagem, de acordo com a cinética de fermentação ruminal.
\end{abstract}

Palavras-chave: lag time, produção de gases, semiárido, valor nutritivo

\begin{abstract}
The aim of this research was to evaluate the silage of 23 sorghum hybrids using the in vitro semiautomatic gas production technique. A completely randomized design with 23 treatments was used, with three replications, and treatments were the sorghum-hybrids silages. Hybrids were grown at the experimental station of the Instituto Nacional do Semiárido (INSA), in Campina Grande - PB. The gas production was estimated using the bicompartimental logistic model, adjusted to the curves of cumulative gas production. A significant effect $(P<0.05)$ was observed for final gas of fibrous carbohydrates (VfCF), which results ranged from 105.99 to $144.53 \mathrm{~mL} / \mathrm{g}$ of DM. Degradation rate of fibrous carbohydrates $(K d C F)$ values ranged $(P<0.05)$ for the hybrid 866041, which showed the highest result $0.015 h^{-1}$. Final total volume (VFT) was affected by hybrid $(P<0.05)$, in which hybrids 870085 , Volumax and XBS60329 had the highest $(P<0.05)$ values compared to other hybrids. By multivariate analysis were formed six distinct groups. Group 2, consisting of hybrids 22 (Volumax) and 23 (XBS60329) showed the highest average values for gas volumes, both for fibrous carbohydrates and for the non-fibrous. Group 4, comprising the hybrid 1 (866005), had the lowest gas volume produced means and a highest lag time (3.15 hours). All hybrids studied have potential to silage, according to the ruminal fermentation kinetics.
\end{abstract}

Keywords: gas production, lag time, nutritional value, semiarid

Recebido em 26 de setembro de 2012

Aceito em 18 de junho de 2014

E-mail: timao22@hotmail.com 


\section{INTRODUÇÃo}

A produção de alimentos para o rebanho constitui, provavelmente, o maior desafio da pecuária do semiárido brasileiro devido à variabilidade climática. A conservação de forragens na forma de silagem pode ser uma alternativa viável para amenizar o problema de escassez nas épocas mais secas do ano. Nesse contexto, a avaliação de híbridos de sorgo (Sorghum bicolor (L.)) é especialmente importante no semiárido brasileiro, pois apresenta resistência/tolerância ao estresse hídrico (Gomes et al., 2006) e permite a seleção de plantas mais adaptadas às condições edafoclimáticas da região.

Estudos comparativos entre híbridos de sorgo são de suma importância, a fim de se fornecerem aos produtores orientações para a escolha de genótipos cujas silagens tenham a melhor relação produção e valor nutritivo (Magalhães et al., 2006). Trabalhos conduzidos no estado da Paraíba, que destacaram o caráter xerofílico da cultura do sorgo (Silva et al., 2011; Macedo et al., 2012; Silva et al., 2012), mostraram que é possível obter elevadas produtividades de matéria seca (MS) combinadas com alto valor nutricional.

Na avaliação de híbridos de sorgo, busca-se aliar características de produção com o valor nutritivo, com o objetivo de se encontrar um equilíbrio para que o desempenho animal não seja comprometido. Assim, com a técnica in vitro semiautomática de produção de gases (Maurício et al., 1999), pode-se descrever a cinética de fermentação ruminal, o que a torna uma ferramenta para avaliação nutricional de forrageiras. Além disso, essa técnica apresenta simplicidade no manuseio de equipamentos e baixo custo na implantação e na análise por amostra (Maurício et al., 2003).

Maurício et al. (2003), em trabalho que avaliou o potencial da técnica in vitro semiautomática de produção de gases para avaliação de silagens de sorgo pela comparação com dados obtidos em experimento in vivo, demonstraram que o método possibilitou a estimativa dos valores de digestibilidade aparente in vivo e forneceu informações adicionais sobre a cinética de fermentação ruminal das silagens avaliadas. Mello et al. (2008) avaliaram os diferentes modelos para ajuste da produção cumulativa de gases em silagens de girassol e milho e concluíram que o modelo logístico bicompartimental apresenta maior qualidade de ajuste às curvas.

Objetivou-se com esta pesquisa avaliar a cinética de fermentação ruminal das silagens de 23 híbridos de sorgo cultivados no semiárido paraibano por meio da técnica in vitro semiautomática de produção de gases.

\section{MATERIAL E MÉTODOS}

O experimento foi conduzido em fevereiro de 2010, no Laboratório de Nutrição Animal da Universidade Estadual de Santa Cruz, pertencente ao município de Ilhéus, Bahia.

Foi utilizado o delineamento inteiramente ao acaso, com 23 tratamentos e três repetições. Os tratamentos foram as silagens de híbridos de sorgo (Sorghum bicolor (L.)) desenvolvidos pelo programa de melhoramento da Embrapa Milho e Sorgo, denominados pelos seguintes nomes ou códigos: 866005, 866019, 866033, 866034, 866035, 866036, 866037, 866040, 866041, 866042, 866043, 866044, 870025, 870031, 870035, 870041, 870051, 870067, 870081, 1F305, 870085, Volumax, XBS60329.

Os híbridos foram cultivados na Estação Experimental do Instituto Nacional do Semiárido (INSA), no município de Campina Grande - PB, onde foram colhidos e ensilados no estádio de grãos farináceos. A ensilagem foi feita em canos de PVC, com $10 \mathrm{~cm}$ de diâmetro e $40 \mathrm{~cm}$ de altura. Após 30 dias, os silos foram abertos, e $300 \mathrm{~g}$ de amostras das silagens de cada silo foram secas parcialmente em estufa com ventilação forçada a $55^{\circ} \mathrm{C}$, até peso constante. Em seguida, foram moídas em peneiras de $2 \mathrm{~mm}$ para se proceder ao ensaio in vitro pela técnica da produção de gases.

As incubações foram realizadas em frascos de vidro com capacidade de $50 \mathrm{~mL}$, onde foi pesado, aproximadamente, 0,30g de cada amostra com três repetições. Aos frascos foram adicionados $28,125 \mathrm{~mL}$ de meio de cultura, previamente reduzido com $\mathrm{CO}_{2}(\mathrm{pH} 6,49)$, e $3,125 \mathrm{~mL}$ de inóculo proveniente de um bovino macho, não castrado, fistulado no rúmen, o qual consumiu silagem de sorgo (híbrido desconhecido) e 
concentrado (18\% de $\mathrm{PB})$. O bovino foi alimentado por quatro semanas até o dia da coleta do líquido ruminal.

Em seguida, os frascos receberam tampa de borracha para completa vedação e foram colocados em uma estufa de ventilação forçada à temperatura controlada de $39^{\circ} \mathrm{C}$, na qual os tubos foram levemente agitados durante intervalos de tempo de fermentação. As leituras de pressão e volume foram tomadas por um transdutor de pressão (PressDATA 800) conectado a uma válvula de três saídas, com uma agulha $(0,6 \mathrm{~mm})$ e uma seringa em cada saída, nos seguintes tempos: uma, duas, três, quatro, seis, oito, 10, 12, 14, 17, 20, 24, 28, 36, 48, 72, 96, 120 e 144 horas. A partir da inserção da agulha na tampa de borracha, a pressão produzida no interior dos frascos foi lida no leitor digital. Os dados de pressão $(\mathrm{P} ;$ psi $=$ pressão por polegada quadrada $)$ foram utilizados para o cálculo do volume de gases produzidos, por meio da equação matemática: $\mathrm{V}(\mathrm{mL})=0,04755+1,9754 \mathrm{P}+$ $0,01407 \mathrm{P}^{2},\left(\mathrm{R}^{2}=0,99\right)$, desenvolvida por Santos et al. (2010), em que V é volume de gás, em mL, e P, pressão, em psi.

A taxa e a extensão da produção de gases foram estimadas para cada repetição por intermédio do ajustamento aos dados de produção de gases do modelo logístico bicompartimental, ajustado às curvas de produção cumulativa de gases (Schofield et al., 1994). As variáveis volume final de carboidratos fibrosos (VfCF), taxa de degradação dos carboidratos fibrosos (KdCF), lag time (L), volume final de carboidratos não fibrosos (VfCNF), taxa de degradação dos carboidratos não fibrosos (KdCNF) e volume final total (VfT) foram ajustadas por regressão não linear pelo método de Gauss-Newton, mediante a utilização do software Sistemas de Análises Estatísticas e Genéticas - SAEG.

Após estimativa das variáveis da cinética de degradação dos carboidratos, foram construídas as curvas de degradação da MS e dos CF e CNF, em função do tempo de incubação. Com o somatório do volume de gás para cada tempo de leitura, puderam ser construídas as curvas de produção cumulativa dos gases oriundos da MS, sendo a curva correspondente à fração solúvel em detergente neutro (CNF) obtida pela diferença entre o gás da MS e o dos CF para cada tempo de incubação.
Os resultados obtidos foram submetidos à análise de variância e, quando necessário, utilizou-se o teste Scott-Knott ao nível de $5 \%$ de probabilidade para agrupar, de forma univariada, as médias de cada híbrido. Aplicou-se o teste proposto por Scott e Knott (1974) devido ao fato de esse ser um método de agrupamento univariado que, diferentemente dos demais testes de comparação de médias múltiplas, elimina a ambiguidade e separa as médias de tratamentos em grupos homogêneos, facilitando, assim, a interpretação, sobretudo quando se trabalha com um elevado número de tratamentos (Santos et al., 2001).

Mediante o uso de todos os parâmetros estimados da cinética de fermentação ruminal, realizou-se a análise multivariada de agrupamento utilizando-se a distância euclidiana média como medida de dissimilaridade; para a delimitação dos grupos, foi empregado o método de otimização de Tocher. As médias dos grupos formados foram comparadas pelo teste de Tukey, a $5 \%$ de probabilidade para o erro tipo I. Todas as análises estatísticas foram realizadas por meio do software Sistemas de Análises Estatísticas e Genéticas - SAEG.

\section{RESULTADOS E DISCUSSÃO}

Na Tab. 1, observam-se os parâmetros estimados da cinética de fermentação ruminal das silagens de híbridos de sorgo. Com relação ao VfCF, observou-se efeito $(\mathrm{P}<0,05)$ de híbridos; os valores variaram de 105,997 a $144,532 \mathrm{~mL} / \mathrm{g}$ de MS para os híbridos 866005 e Volumax, respectivamente, com média de $125,28 \mathrm{~mL} / \mathrm{g}$ de MS. Observou-se que, para essa variável, formaram-se dois grupos, um acima de $126 \mathrm{~mL} / \mathrm{g}$ de MS e outro abaixo desse valor. O volume de gás produzido depende da natureza do alimento, mais precisamente de sua composição, pois quanto maior a quantidade de fibra, maior a produção de gases, e quanto maior o teor de amido, menor a produção (Nogueira et al., 2008). Isto permite inferir que o grupo que apresentou VfCF superior a $126 \mathrm{~mL} / \mathrm{g}$ de MS é composto por plantas mais digestíveis no que diz respeito à fração fibrosa. Como nas forrageiras tropicais o principal fator limitante é a qualidade da fibra, quanto maior for a sua degradabilidade, maior será a passagem do alimento pelo trato gastrointestinal e, consequentemente, maior será o consumo. Com isso, esses híbridos podem ser 
selecionados para avaliação em ensaios de consumo e desempenho animal.

Os valores médios da KdCF variaram $(\mathrm{P}<0,05)$ entre os híbridos, e o 866041 destacou-se entre os demais, com $0,015 \mathrm{~h}^{-1}$, enquanto a média geral foi de $0,011 \mathrm{~mL} / \mathrm{g}$ de $\mathrm{MS} / \mathrm{h}$. Os carboidratos estruturais possuem capacidade de degradação mais lenta; por esse motivo, a taxa de degradação de carboidratos fibrosos (KdCF) é inferior à taxa de degradação de carboidratos não fibrosos (KdCNF), 0,011 e 0,065mL/g de MS/h, respectivamente (Tab. 1 ).
A variável tempo de colonização ou lag time (L) não diferiu $(\mathrm{P}>0,05)$ entre os tratamentos, e a média geral observada foi de 2,221h (Tab. 1). Essa variável indica o tempo envolvido entre o início da incubação e a ação microbiana sobre a amostra; por conseguinte, quanto maior a presença de substâncias solúveis prontamente fermentáveis e características físicas e químicas da parede celular da amostra, capazes de facilitar a colonização microbiana, menor será o tempo de colonização (Magalhães et al., 2006).

Tabela 1. Parâmetros estimados da cinética de fermentação ruminal de silagens de híbridos de sorgo

\begin{tabular}{ccccccc}
\hline \multirow{2}{*}{ Híbridos } & VfCF & KdCF & $\mathrm{L}$ & VfCNF & KdCNF & VfT \\
\cline { 2 - 6 } & mL/g de MS & $\mathrm{h}^{-1}$ & $\mathrm{~h}$ & $\mathrm{~mL} / \mathrm{g} \mathrm{de} \mathrm{MS}$ & $\mathrm{h}^{-1}$ & $\mathrm{~mL} / \mathrm{g}$ de MS \\
\hline 866005 & $105,997 \mathrm{~b}$ & $0,010 \mathrm{~b}$ & 3,147 & 56,591 & $0,063 \mathrm{~b}$ & $162,587 \mathrm{~b}$ \\
866019 & $120,887 \mathrm{~b}$ & $0,013 \mathrm{~b}$ & 3,147 & 61,210 & $0,080 \mathrm{a}$ & $182,097 \mathrm{~b}$ \\
866033 & $121,283 \mathrm{~b}$ & $0,012 \mathrm{~b}$ & 2,792 & 61,631 & $0,065 \mathrm{~b}$ & $182,913 \mathrm{~b}$ \\
866034 & $117,637 \mathrm{~b}$ & $0,012 \mathrm{~b}$ & 2,678 & 59,464 & $0,068 \mathrm{~b}$ & $177,101 \mathrm{~b}$ \\
866035 & $121,229 \mathrm{~b}$ & $0,012 \mathrm{~b}$ & 1,993 & 58,824 & $0,076 \mathrm{a}$ & $180,054 \mathrm{~b}$ \\
866036 & $128,339 \mathrm{a}$ & $0,012 \mathrm{~b}$ & 2,199 & 55,952 & $0,075 \mathrm{a}$ & $184,291 \mathrm{~b}$ \\
866037 & $129,561 \mathrm{a}$ & $0,012 \mathrm{~b}$ & 2,430 & 50,698 & $0,080 \mathrm{a}$ & $180,26 \mathrm{~b}$ \\
866040 & $122,181 \mathrm{~b}$ & $0,013 \mathrm{~b}$ & 1,621 & 61,910 & $0,075 \mathrm{a}$ & $184,091 \mathrm{~b}$ \\
866041 & $134,037 \mathrm{a}$ & $0,015 \mathrm{a}$ & 2,431 & 54,660 & $0,084 \mathrm{a}$ & $188,697 \mathrm{~b}$ \\
866042 & $124,554 \mathrm{~b}$ & $0,011 \mathrm{~b}$ & 2,548 & 61,010 & $0,061 \mathrm{c}$ & $185,561 \mathrm{~b}$ \\
866043 & $121,504 \mathrm{~b}$ & $0,011 \mathrm{~b}$ & 1,765 & 57,230 & $0,070 \mathrm{~b}$ & $178,732 \mathrm{~b}$ \\
866044 & $126,381 \mathrm{a}$ & $0,010 \mathrm{~b}$ & 2,202 & 57,624 & $0,051 \mathrm{c}$ & $184,005 \mathrm{~b}$ \\
870025 & $117,624 \mathrm{~b}$ & $0,010 \mathrm{~b}$ & 0,975 & 67,859 & $0,041 \mathrm{c}$ & $185,483 \mathrm{~b}$ \\
870031 & $118,734 \mathrm{~b}$ & $0,012 \mathrm{~b}$ & 2,002 & 58,076 & $0,065 \mathrm{~b}$ & $176,81 \mathrm{~b}$ \\
870035 & $125,122 \mathrm{~b}$ & $0,010 \mathrm{~b}$ & 2,270 & 58,262 & $0,050 \mathrm{c}$ & $183,384 \mathrm{~b}$ \\
870041 & $131,946 \mathrm{a}$ & $0,011 \mathrm{~b}$ & 1,919 & 48,862 & $0,064 \mathrm{~b}$ & $180,808 \mathrm{~b}$ \\
870051 & $123,402 \mathrm{~b}$ & $0,011 \mathrm{~b}$ & 2,494 & 59,194 & $0,062 \mathrm{~b}$ & $182,596 \mathrm{~b}$ \\
870067 & $122,769 \mathrm{~b}$ & $0,012 \mathrm{~b}$ & 2,136 & 54,629 & $0,074 \mathrm{a}$ & $177,398 \mathrm{~b}$ \\
870081 & $127,860 \mathrm{a}$ & $0,010 \mathrm{~b}$ & 2,492 & 57,572 & $0,060 \mathrm{c}$ & $185,432 \mathrm{~b}$ \\
$1 \mathrm{~F} 305$ & $133,582 \mathrm{a}$ & $0,011 \mathrm{~b}$ & 1,291 & 67,376 & $0,0740 \mathrm{~b}$ & $200,958 \mathrm{a}$ \\
870085 & $127,470 \mathrm{a}$ & $0,010 \mathrm{~b}$ & 2,211 & 63,537 & $0,037 \mathrm{c}$ & $191,007 \mathrm{~b}$ \\
Volumax & $144,532 \mathrm{a}$ & $0,011 \mathrm{~b}$ & 2,324 & 58,961 & $0,0602 \mathrm{c}$ & $203,493 \mathrm{a}$ \\
XBS60329 & $134,804 \mathrm{a}$ & $0,011 \mathrm{~b}$ & 2,022 & 67,280 & $0,0514 \mathrm{c}$ & $202,084 \mathrm{a}$ \\
\hline Média & 125,28 & 0,011 & 2,221 & 59,061 & 0,065 & 184,341 \\
\hline CVV (\%) & 6,03 & 11,7 & 27,13 & 13,39 & 13,87 & 4,65 \\
\hline
\end{tabular}

VfCF: volume final de carboidratos fibrosos; KdCF: taxa de degradação dos carboidratos fibrosos; VfCNF: volume final de carboidratos não fibrosos; KdCNF: taxa de degradação dos carboidratos não fibrosos; L: lag time e VfT: volume final total.

O VfCNF não diferiu $(\mathrm{P}>0,05)$ entre os tratamentos, e a média geral foi de $59,061 \mathrm{~mL} / \mathrm{g}$ de MS. Foram observadas diferenças $(\mathrm{P}<0,05)$ entre as médias de KdCNF, com os resultados variando de 0,084 a $0,036 \mathrm{~mL} / \mathrm{g}$ de $\mathrm{MS} / \mathrm{h}$, com média de $0,064 \mathrm{~mL} / \mathrm{g}$ de $\mathrm{MS} / \mathrm{h}$. Os híbridos 866019, 866035, 866036, 866037, 866040 e 866041 apresentaram maiores resultados
$(\mathrm{P}<0,05)$ em relação aos demais. Mesmo apresentando produção de gás semelhante para o CNF, a maior taxa de degradação é desejável e pode estar associada à maior quantidade de substratos prontamente fermentáveis, como carboidratos solúveis. 
O volume final total (VfT) de gás variou entre os tratamentos $(\mathrm{P}<0,05)$, sendo que os híbridos Volumax, XBS 60329 e 870085 apresentaram maior média em relação aos demais, 203,49, 202,08 e 200,96mL/g de MS, respectivamente. Esse destaque no VfT pode ser atribuído aos maiores valores de VfCF, uma vez que os valores de VfCNF não diferiram, sabendo-se que a produção total de gás foi obtida pelo somatório do VfCF e VfCNF. É importante destacar que a maior parte do volume de gases produzido é oriunda dos compostos de lenta degradação (carboidratos fibrosos), pois o modelo logístico bicompartimental divide a produção total de gases em dois compartimentos distinguidos pelas suas taxas de digestão (rápida e lenta). No presente trabalho, em média, o VfCF e o VfCNF representaram 67 e $33 \%$ do VfT, respectivamente.
Ao analisarem o valor nutricional das silagens do sorgo BRS-610 em sete estádios de maturação, utilizando a técnica in vitro semiautomática de produção de gases, Faria Júnior et al. (2010) observaram que a produção cumulativa de gases foi de 181,706mL/g de MS aos 96 dias de incubação, valor esse inferior ao encontrado para o mesmo híbrido do presente experimento, 191,007mL/g de MS (Tab. 1), no mesmo estádio de maturidade (grãos farináceos). Todavia, a maior produção de gás encontrada pode estar associada ao maior tempo de incubação utilizado no presente estudo (144 horas), que permitiu maior tempo de contato do material com a fonte de inóculo.

A análise de agrupamento pelo método de otimização de Tocher, com base na distância euclidiana média padronizada, possibilitou a formação de seis grupos (Tab. 2).

Tabela 2. Agrupamento de 23 híbridos de sorgo, com base nos parâmetros de produção de gás in vitro das silagens, utilizando-se o método de otimização de Tocher e a distância euclidiana média

\begin{tabular}{cl} 
Grupo & \multicolumn{1}{c}{ Híbrido } \\
\hline 1 & 866042, 870051, 870081, 866033, 866044, 870035, 870041, 870067, 866043, 870031, 866036, 866035, \\
2 & 866034, 866037, 866040, 870085 \\
3 & Volumax, XBS60329 \\
4 & 866019,866041 \\
5 & 866005 \\
6 & $1 F 305$ \\
\hline
\end{tabular}

Na Tab. 2, observa-se que 16 dos 23 híbridos avaliados ficaram no mesmo grupo (grupo 1) e os demais grupos foram formados por, no máximo, dois híbridos. Os demais grupos, com um e dois híbridos, permitem a identificação de híbridos diferenciados, com base nas características analisadas.

Na Tab. 3, é possível observar que os grupos 1, 6 , 5 e 3 apresentaram características intermediárias quanto às variáveis da produção de gás. Isto mostra que a maioria dos híbridos apresentou uniformidade no que diz respeito à cinética de fermentação. No entanto, o grupo 2 destacou-se em relação aos demais com maior VfCF, VfCNF e VfT $(\mathrm{P}<0,05)$. Portanto, forrageiras mais fermentáveis ou digestíveis seriam aquelas com maiores valores de potencial máximo associado a altas taxas de produção de gás, resultando numa maior fermentação do material em menor tempo de incubação (Guimarães Jr. et al., 2008).
Ao se realizar o agrupamento multivariado, foi possível observar um refinamento na classificação dos híbridos em relação a algumas variáveis, como o VfCF, sendo os maiores $(\mathrm{P}<0,05)$ valores observados para o grupo 2 , composto pelos híbridos Volumax e XBS60329. A superioridade desses híbridos, principalmente para os valores de VfCF, pode ser atribuída ao maior teor de hemicelulose, o que demonstra maior digestibilidade da fibra, conforme observado por Silva et al. (2012). Os valores de VfCF observados para o grupo 2 foram semelhantes $(\mathrm{P}>0,05)$ aos dos grupos 3 e 6 , evidenciando-se, assim, o potencial dos híbridos pertencentes a esses grupos em apresentar maior degradação dos componentes fibrosos. É importante ressaltar que o híbrido 1F305 (grupo 6), mesmo sendo de caráter forrageiro, com participação do componente colmo na MS acima de 70\% (Silva et al., 2011), apresentou superioridade em relação aos híbridos dos demais grupos caracterizados como de duplo propósito. 
Tabela 3. Parâmetros estimados da cinética de fermentação ruminal dos grupos de híbridos de sorgo

\begin{tabular}{ccccccc}
\hline Grupo & $\begin{array}{c}\text { VfCF } \\
\text { mL/g de MS }\end{array}$ & $\begin{array}{c}\text { KdCF } \\
\mathrm{h}^{-1}\end{array}$ & $\begin{array}{c}\mathrm{L} \\
\mathrm{h}\end{array}$ & $\begin{array}{c}\text { VfCNF } \\
\mathrm{mL} / \mathrm{g} \text { de } \mathrm{MS}\end{array}$ & $\begin{array}{c}\text { KdCNF } \\
\mathrm{h}^{-1}\end{array}$ & $\begin{array}{c}\text { VfT } \\
\mathrm{mL} / \mathrm{g} \text { de MS }\end{array}$ \\
\hline 1 & $124,167 \mathrm{~b}$ & $0,0113 \mathrm{~b}$ & $2,236 \mathrm{ab}$ & 57,396 & $0,066 \mathrm{a}$ & $181,562 \mathrm{~b}$ \\
2 & $137,639 \mathrm{a}$ & $0,011 \mathrm{bc}$ & $\begin{array}{c}1,879 \mathrm{bc} \\
2,789 \mathrm{ab}\end{array}$ & 57,539 & $0,062 \mathrm{abc}$ & $202,178 \mathrm{a}$ \\
3 & $127,462 \mathrm{ab}$ & $0,014 \mathrm{a}$ & 2,735 & $0,082 \mathrm{a}$ & $185,397 \mathrm{~b}$ \\
4 & $105,996 \mathrm{c}$ & $0,010 \mathrm{bc}$ & $3,147 \mathrm{a}$ & 56,591 & $0,063 \mathrm{ab}$ & $162,587 \mathrm{c}$ \\
5 & $117,624 \mathrm{bc}$ & $0,010 \mathrm{bc}$ & $0,975 \mathrm{c}$ & 67,859 & $0,041 \mathrm{bc}$ & $185,483 \mathrm{~b}$ \\
6 & $127,470 \mathrm{ab}$ & $0,010 \mathrm{c}$ & $2,211 \mathrm{ab}$ & 63,537 & $0,037 \mathrm{c}$ & $191,007 \mathrm{ab}$ \\
$\mathrm{CV}(\%)$ & 6,19 & 11,74 & 27,77 & 12,89 & 17,32 & 4,24 \\
\hline
\end{tabular}

VfCF: volume final de carboidratos fibrosos; KdCF: taxa de degradação dos carboidratos fibrosos; L: lag time; VfCNF: volume final de carboidratos fibrosos; KdCNF: taxa de degradação dos carboidratos fibrosos e VfT: volume final total.

Maurício et al. (2003) analisaram o potencial da técnica in vitro semiautomática de produção de gases para avaliação de silagens de sorgo, sendo dois forrageiros, BR601 e AG2002, e dois de duplo propósito, BR700 e BR701. Os autores observaram que o potencial máximo de produção de gás variou $(\mathrm{P}<0,05)$ entre os híbridos estudados, com destaque para o BR 601 $(198 \mathrm{~mL})$, e que a menor média foi observada no AG2002 (167mL) após 96 horas de incubação. Esses valores são inferiores aos dos híbridos do grupo 2 (Tab. 3).

A análise multivariada possibilitou a formação de grupos mais homogêneos e, por isso, as diferenças que anteriormente não eram significativas passaram a ser, como foi observado para a variável lag time $(\mathrm{P}<0,05)$. Os menores $(\mathrm{P}<0,05)$ valores foram observados para os híbridos dos grupos 2 e 5; este último, entretanto, não apresentou diferenças $(\mathrm{P}>0,05)$ em relação aos grupos 1 , 3 e 6 . Para o início da degradação do alimento no rúmen, o primeiro passo é a aderência da célula bacteriana ao alimento (Weimer, 1996), a qual ocorre, inicialmente, por meio da adesão não específica (interações aniônicas, hidrofóbicas e forças de Van Der Walls), seguida da interação específica entre receptores na superfície da partícula e moléculas denominadas adesinas (presentes na superfície externa da bactéria) e da formação de colônias bacterianas ou biofilmes (Miron, 2001), definidos como matrizes compactas de populações bacterianas aderidas entre si e a superfície da partícula (Kozloski, 2009).
Consequentemente, tecidos mais lignificados apresentam maior resistência à colonização e à degradação, como pode ter sido o caso do híbrido 866005, que apresentou maior $(\mathrm{P}<0,05)$ teor de fibra em detergente ácido (FDA) e menor concentração de hemicelulose, conforme dados apresentados por Silva et al. (2012).

O grupo 4, formado pelo híbrido 866005, foi o que apresentou os menores valores $(\mathrm{P}<0,05)$ médios de VfCF, VfCNF e VfT. A baixa produção de gases desse híbrido pode estar associada à presença de tanino, ou ao elevado teor de lignina.

Não foram observadas diferenças $(\mathrm{P}>0,05)$ entre as médias dos grupos para o VfCNF, entretanto a taxa de degradação dessa fração (KdCNF) apresentou diferenças $(\mathrm{P}<0,05)$ entre os grupos, sendo a menor média observada para o grupo 6 $\left(0,037 \mathrm{~h}^{-1}\right)$, a qual diferiu apenas das médias dos grupos 1, 3 e 4 . As diferenças nas KdCNF dos grupos avaliados podem ser ocasionadas pela composição dos CNF dessas silagens, uma vez que as frações que os compõem apresentam taxas de degradação diferentes, como descrito por Van Amburgh et al. (2010).

Os gráficos da cinética de produção cumulativa de gases foram gerados apenas para os grupos 2 , 4 e 6 , de forma a obter uma representatividade de todos os híbridos avaliados, incluindo um grupo com valores de produção de gás superiores, um intermediário e um inferior (Fig. 1, 2 e 3). 
Cinética de fermentação...

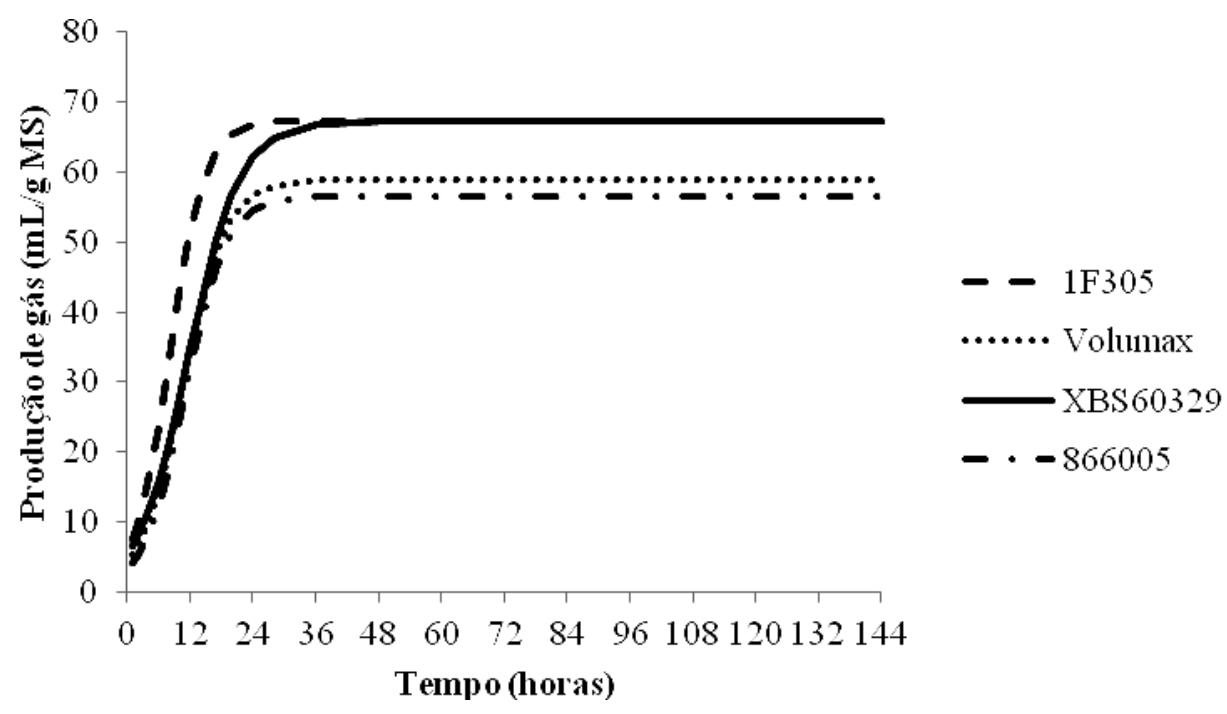

Figura 1. Cinética de produção de gás in vitro dos carboidratos não fibrosos das silagens de híbridos de sorgo.

Na Fig. 1, é possível observar que o híbrido 1 F305 apresentou uma degradação mais acentuada até as 24 horas de incubação, quando a produção de gás se igualou à do XBS60329. Os demais híbridos também apresentaram a máxima produção perto de 24h, entretanto os valores foram menores. Observou-se também que, independentemente do tempo, a degradação dos CNF da silagem do híbrido 866005 foi menor. O modelo da produção de gases assume que a produção de massa bacteriana e de gases é proporcional à quantidade de substrato digerido (Schofield et al., 1994).

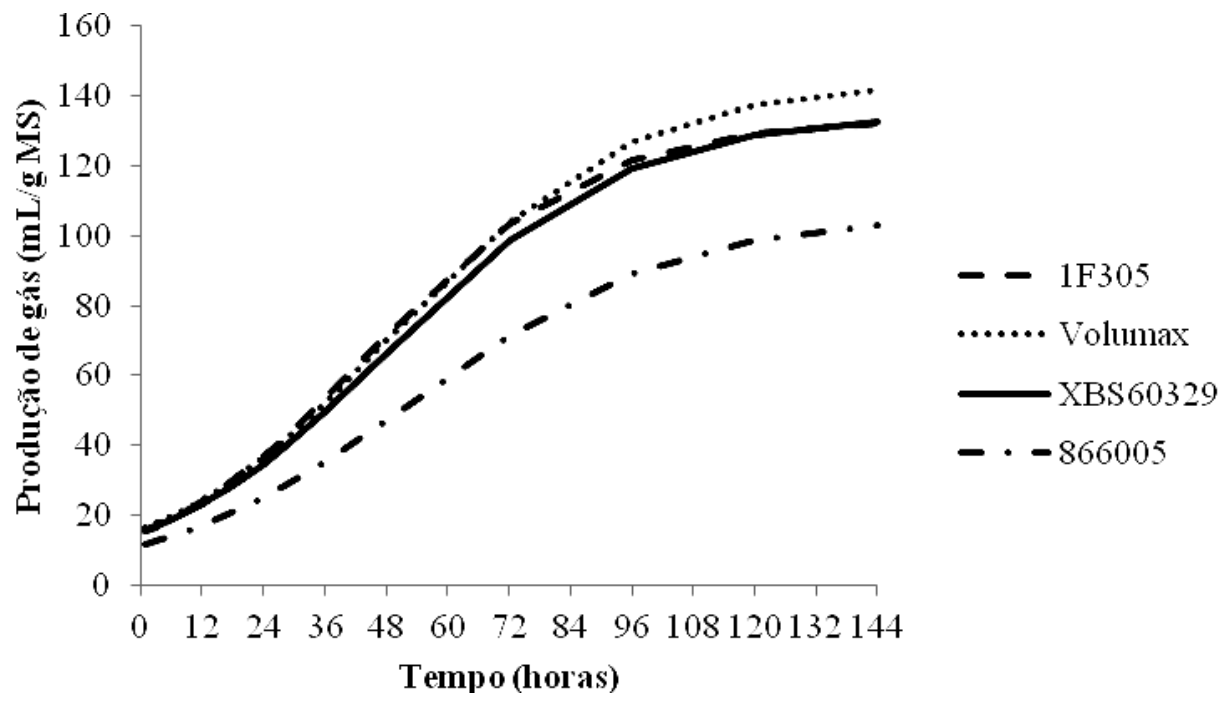

Figura 2. Cinética de produção de gás in vitro dos carboidratos fibrosos das silagens de híbridos de sorgo.

Os gráficos de cinética fermentativa mostram que a degradação dos carboidratos fibrosos ocorre de forma mais lenta, devido aos fatores citados anteriormente, como adesão e colonização bacteriana, bem como o teor de lignificação da parede celular. Até 72 horas após a incubação, os híbridos Volumax e 1 F305 apresentaram a mesma taxa de degradação, mas, logo em seguida, o Volumax apresentou produção de gás superior (Fig. 2). Guimarães Jr. 
et al. (2008) avaliaram a degradabilidade da MS e a cinética de fermentação (seis a 96 horas) ruminal das silagens de três genótipos de milheto (BRS-1501, NPM-1 e CMS-3), determinadas por meio da técnica in vitro semiautomática de produção de gases, e verificaram que maiores taxas de produção de gás foram obtidas no período de seis horas de fermentação, fato provavelmente ligado à fermentação dos carboidratos prontamente disponíveis. Já entre os períodos de 14 e 24 horas, observaram uma segunda elevação na produção de gases por hora, que pode estar relacionada à fermentação dos carboidratos fibrosos.

Resultados semelhantes foram encontrados por Jayme et al. (2009), que, ao avaliarem a produção de gás das silagens de quatro genótipos de girassol, verificaram que as maiores $m$ é dias foram obtidas no período entre zero e seis horas de fermentação. Os autores também observaram uma ligeira elevação na produção de gases por hora entre os períodos de 12 e 18 horas, que também pode estar relacionada à fermentação dos carboidratos fibrosos.

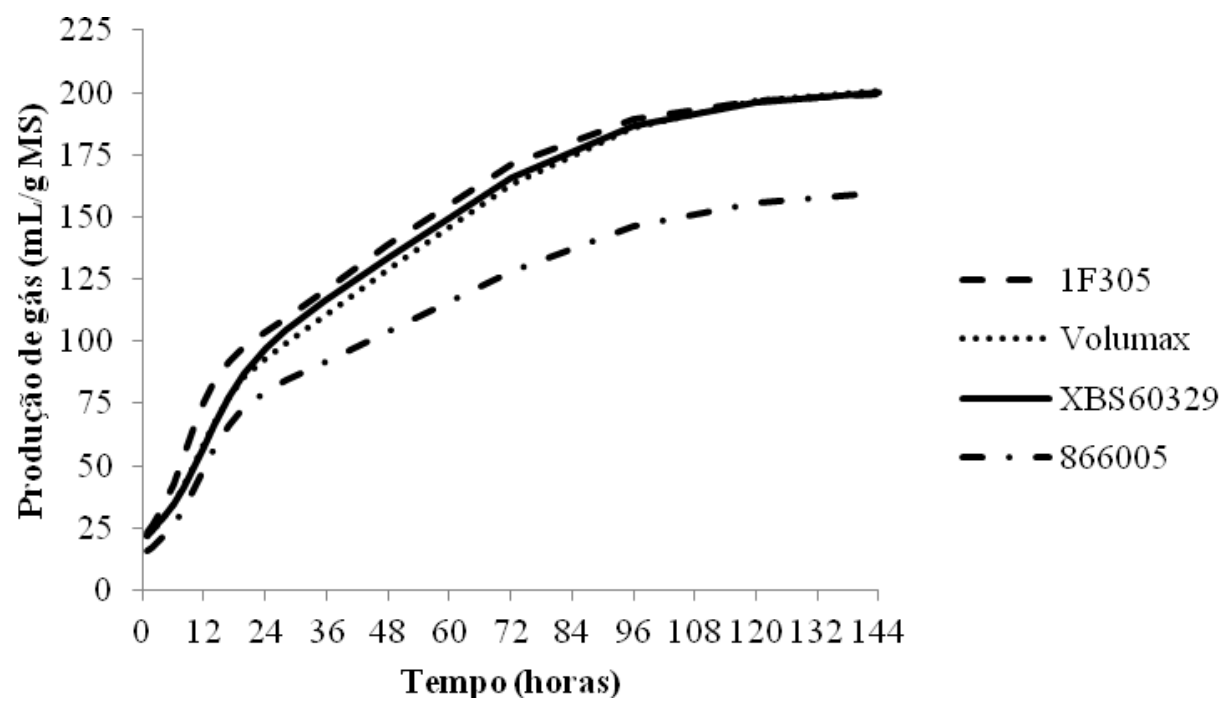

Figura 3. Cinética de produção de gás in vitro dos carboidratos totais das silagens de híbridos de sorgo.

Após a análise de agrupamento com base na cinética de fermentação, pode-se inferir que os grupos formados apresentam homogeneidade e que os valores de produção de gás observados no presente trabalho encontram-se iguais ou superiores aos observados na literatura, como discutido.

A silagem do híbrido 866005, segundo Silva et al. (2012), não apresentou qualquer característica fermentativa ou da composição bromatológica que fosse limitante, mesmo fazendo parte do grupo dos híbridos com maiores teores de fibra em detergente ácido (FDA). Entretanto, na avaliação pela técnica da produção de gases, os parâmetros observados foram sempre inferiores (Fig. 1, 2 e 3). Como todos esses genótipos avaliados fazem parte de um programa de melhoramento, essas informações poderão auxiliar no ranqueamento desses híbridos, considerando-se as características agronômicas e o valor nutritivo. Nesse aspecto, apenas alguns desses híbridos poderiam ser utilizados em ensaios com animais.

\section{CONCLUSÕES}

As silagens dos híbridos Volumax, 1F305 e XBS60329 apresentam superioridade quanto aos parâmetros de cinética de fermentação ruminal. Os híbridos estudados não apresentam limitações nutricionais, de acordo com a cinética de fermentação ruminal. 


\section{REFERÊNCIAS}

FARIA Jr., W.G.; GONÇALVES, L.C.; MAURÍCIO, R.M. et al. Avaliação das silagens do sorgo BRS-610 em sete estádios de maturação pela técnica in vitro semiautomática de produção de gases. Arq. Bras. Med. Vet. Zootec., v.62, p.898905, 2010.

GUIMARÃES Jr., R.; GONÇALVES, L.C.; MAURÍCIO, R.M. et al. Cinética de fermentação ruminal de silagens de milheto. Arq. Bras. Med. Vet. Zootec., v.60, p.1174-1180, 2008.

GOMES, S.O.; PITOMBEIRA, J.B.; NEIVA, J.N.M. et al. Comportamento agronômico e composição químico-bromatológico de cultivares de sorgo forrageiro no Estado do Ceará. Rev. Cienc. Agron., v.37, p.221-227, 2006.

JAYME, D.G.; GONÇALVES, L.C.; MAURÍCIO, R.M. et al. Avaliação pela técnica semiautomática de produção de gases das silagens de quatro genótipos de girassol (Helianthus annuus) (Rumbosol 91, Victoria 627, Victoria 807 e Mycogen 93338). Arq. Bras. Med. Vet. Zootec., v.61, p.1403-1410, 2009.

KOZLOSKI, G.V. Bioquímica dos ruminantes. 2. ed. - Santa Maria: Ed. UFSM, 2009. 216p.

MACEDO, C.H.O.; ANDRADE, A.P.; SANTOS, E.M. et al. Perfil fermentativo e composição bromatológica de silagens de sorgo em função da adubação nitrogenada. Rev. Bras. Saúde Prod. Anim., v.13, p.371-382, 2012.

MAGALHÃES, R.T.; GONÇALVES, L.C.; MAURÍCIO, R.M. et al. Avaliação de quatro genótipos de sorgo pela técnica "in vitro" semiautomática de produção de gases. Rev. Bras. Milho e Sorgo, v.5, p.101-111, 2006.

MAURÍCIO, R.M.; MOULD, F.L.; DHANOA, M.S. et al. A semi-automated in vitro gas production technique for ruminants feedstuff evaluation. Anim. Feed Sci. Technol., v.79, p.321330,1999 .

MAURÍCIO R.M.; PEREIRA L.G.R.; GONÇALVES .L.C. et al. Relação entre pressão e volume para implantação da técnica in vitro semiautomática de produção de gases na avaliação de forrageiras tropicais. Arq. Bras. Med. Vet. Zootec., v.55, p.216-219, 2003.
MELLO, R..; MAGALHAES A.L.R.; BREDA, F.C. et al. Modelos para ajuste da produção de gases em silagens de girassol e milho. Pesq. agropec. bras., v.43, p.261-269, 2008.

MIRON, J.; BEN-GHEDALIA, D.; MORRISON, $M$. et al. Invited review: adhesion mechanisms of rumen cellulolytic bacteria. J. Dairy Sci., v.84, p.1294-1309, 2001.

NOGUEIRA, U.T.; MAURÍCIO, R.M.; GONÇALVES, L.C. Comparação de substratos com diferentes quantidades de carboidratos solúveis utilizando a técnica in vitro semi-automática de produção de gases. Arq. Bras. Med. Vet. Zootec., v.58, p.901-909, 2006.

SANTOS, C.; FERREIRA, D.F.; BUENO FILHO, J.S.S. Novas alternativas de testes de agrupamento avaliadas por meio de simulação monte carlo. Cienc. Agrotec., v.25, p.1382-1392, 2001.

SANTOS, M.G.M.F.; AZEVEDO, J.A.G.; PEREIRA, L.G.R. et al. Relação entre pressão e volume para implantação da técnica in vitro de produção de gases no trópico úmido. In: REUNIÃO ANUAL DA SOCIEDADE BRASILEIRA DE ZOOTECNIA, 47., 2010, Salvador. Anais ..., Salvador, 2010.

SILVA, T.C; SANTOS, E.M.; AZEVEDO, J.A.G. et al. Agronomic divergence of sorghum hybrids for silage yield in the semiarid region of Paraiba. Rev. Bras. Zootec. (Online), v.40, p.1886-1893, 2011.

SILVA, T.C; SANTOS, E.M.; MACEDO, C.H.O. et al. Divergence of the fermentative and bromatological characteristics of 25 sorghum hybrid silages. Rev. Bras. Zootec. (Online), v.41, p.1127-1133, 2012.

SCHOFIELD, P.; PITT, R.E.; PELL, A.N. Kinetics of fiber digestion from in vitro gas production. $J$. Anim Sci., v.72, p.2980-2991, 1994.

SISTEMA de análises estatísticas e genéticas SAEG. Viçosa: Universidade Federal de Viçosa, 2000. Manual do usuário, 138p. (versão 9.0).

VAN AMBURGH, M.E., RECKTENWALD, E.B.; ROSS, D.A. et al. Updates to the Cornell Net Carbohydrate and Protein System. In: Proc. Cornell Nutr. Conf. Syracuse, NY, p.144-159, 2010.

WEIMER, P.J. Why don't ruminal bacteria digest cellulose faster? J. Dairy Sci., v.79, p.1496-1502, 1996. 